\title{
Incidence of complications in bronchoscopy. Multicentre prospective study of 20,986 bronchoscopies
}

\author{
N. Facciolongo1, M. Patelli2, S. Gasparini3, L. Lazzari Agli4, \\ M. Salio5, C. Simonassi6, B. Del Prato7, P. Zanoni8
}

ABSTRACT: Incidence of complications in bronchoscopy. Multicentre prospective study of 20,986 bronchoscopies. N. Facciolongo, M. Patelli, S. Gasparini, L. Lazzari Agli, M. Salio, C. Simonassi, B. Del Prato, P. Zanoni.

Aim. To evaluate the frequency of complications in bronchoscopy from data compiled between 1/2/2002 to 1/2/2003 .

Materials and methods. Nineteen Italian centres of thoracic endoscopy participated in the study, for a total of 20,986 bronchoscopies (FBS), including 10,658 explorative bronchoscopies (EB) (50.79\%), 5,520 bronchial biopsies (BB) $(26.30 \%), 1,660$ transbronchial biopsies (TBB) (7.91\%), 1,127 broncho-alveolar lavages (BAL) (5.37\%), 930 transbronchial needle-aspirates (TBNA) $(4.43 \%)$, 1.091 therapeutic bronchoscopies (TB), comprising NDYAG Laser, argon-plasma, electrocautery knife, stent insertion $(5.20 \%) .82 .4 \%$ of the procedures involved the use of a flexible bronchoscope, $16.3 \%$ were carried out using a rigid bronchoscope and $1.3 \%$ using the mixed technique.
Results. The total number of complications recorded was $227(1.08 \%$ of the cases examined), including 20 $(\mathbf{0 . 0 9 \%})$ during local anesthesia and pre-medication, 195 $(0.92 \%)$ during the endoscopic procedures and $12(0.05 \%)$ in the two hours following FBS. The total number of deaths was $4(0.02 \%)$, due to cardiac arrest, pulmonary edema, delayed respiratory failure and shock in pre-medication, respectively. $68.28 \%$ of the complications were treated medically, $25.99 \%$ by means of endoscopy and $5.72 \%$ with surgery. The healing percentage was $98.2 \%$.

Conclusions. This study has shown that bronchoscopy is a safe method with low incidence of mortality and complications. The preparation, experience and continuous training of the operators of the medical and nursing team seem to play a fundamental role in reducing the incidence of complications at least in certain procedures such as BB and TBB.

Monaldi Arch Chest Dis 2009; 71: 1, 8-14.

Keywords: Bronchoscopy, Complications, Bronchial biopsies, Transbronchial biopsies, Hemorrhage, Pneumothorax.

1 Pulmonary diseases Unit, Santa Maria Nuova Hospital, Reggio Emilia;

2 Thoracic Endoscopy e Pneumology Unit; Maggiore-Bellaria Hospital; Azienda USL Bologna;

3 Pulmonary diseases Unit, Departement of Internal Medicine, Immunoallergic and Respiratory Diseases; Azienda Ospedaliera Universitaria "Ospedali Riuniti" Ancona;

4 Pulmonary diseases Unit, Rimini Hospital;

5 Pulmonary diseases Unit, SS. Antonio e Biagio e C. Arrigo Hospital, Alessandria;

6 Interventional Pneumology Unit, Villa Scassi Hospital, Genoa;

7 Bronchial Endoscopy and Bronchial Emergencies Unit, “A. Cardarelli” Hospital, Naples;

8 Statistical Service, Santa Maria Nuova Hospital, Reggio Emilia, Italy.

Correspondence: Nicola Facciolongo M.D. Cardiothoracic and Critical Area Dept. S.C. Pneumology, Santa Maria Nuova Hospital, Reggio Emilia, Via Risorgimento 80, 42100 Reggio Emilia, Italy; e-mail: facciolongo.nicola@asmn.re.it

\section{Introduction}

In the last twenty years, bronchoscopy (FBS) has undergone very significant developments with an amplification of the procedures which have become increasingly complex and invasive, without strong evidence of the possible increase in the incidence and type of complications.

There have been very few studies carried out on this topic. In 1974 Creedle [1] published the first retrospective study of the complications that occur in bronchoscopy, conducted by means of a questionnaire sent to 250 pneumology specialists. Among those interviewed, 78\% replied, a sample of 24,521 bronchoscopies was collected, showing a mortality rate of $0.1 \%$ and an incidence of com- plications greater than $0.8 \%$. In 1976 Suratt [2] published a very similar study with a lower percentage of replies from those interviewed (31\% of 1041 questionnaires sent out) but obtaining a sample of 48,000 bronchoscopies. The mortality was found to be $0.03 \%$ and the complications were more than $0.3 \%$. In 1978, Pereira [3] published the first multicentre prospective study on a sample of 908 patients, recording a mortality of $0.1 \%$ and incidence of complications equal to $1.7 \%$. Other authors reported higher percentages of incidence, for retrospective studies, like Dreisin [4] who reported a mortality of $0.5 \%$ and an incidence of complications greater than and less than 5 and $6 \%$, respectively, for 205 procedures, while Burger [5] reported an incidence of hemorrhages and pneumothorax 
equal to $30.2 \%$ on a sample of 78 patients subjected to transbronchial biopsy. Sympson [6] and Smyth [7] published two surveys on the habits of British endoscopists, where the data for incidence of complications and mortality reported was $0.12 \%$ and $0.04 \%$, respectively.

\section{Materials and methods}

We designed a prospective multicentre study to evaluate the real incidence of complications in Bronchoscopy (FBS) and the type in relation to all the new diagnostic and therapeutic methods. The study was conducted during the period from $01 / 02 / 2002$ to $01 / 02 / 2003$. Nineteen Italian endoscopy centres participated in the study by compiling a chart via the website with access reserved for each participating centre by means of a password. The chart contained general information regarding the centres, the diagnostic procedures, the number and type of complication that occurred. The chart proposed was validated by the Interventional Pneumology study team of the Italian Association of Hospital Pneumologists (AIPO). The procedures and the complications were coded for better statistical processing and to facilitate data entry. We defined a "complication" as any adverse event directly correlated with the endoscopic procedure performed. The complications were classified as: complications that occurred during the preparation for the examination (local anesthesia and pre-medication, if any), complications that occurred during the endoscopic procedure and the delayed complications that occurred within 2 hours of the end of the procedure. We defined the oxyhaemoglobin desaturation during the bronchoscopy procedure as a 6 point percentage drop in the oxyhaemoglobin saturation from that recorded at the beginning of the procedure. We define haemorrhage as bleeding caused by procedure. We distinguish: mild haemorrhage $<50 \mathrm{ml}$ and severe haemorrhage $>50 \mathrm{ml}$.

The data was recorded in a database (ACCESS-OFFICE 2000- Microsoft inc.) and statistical analysis was carried out using the SPSS version 15.0 program. The sample was divided into two categories: the first group of explorative bronchoscopies which involves only endoscopic exploration and broncho-aspirates without other interventional procedures; the second group of non-explorative bronchoscopies which comprises endoscopic exploration associated with interventional procedures like bronchial biopsies (BB), transbronchial biopsies (TBB), transbronchial needle aspirates (TBNA), broncho-alveolar lavage (BAL), therapeutic bronchoscopies (TB) (Nd Yag laser, argon plasma, stent positioning, electrocautery etc.). The descriptive analysis was carried out only on the non explorative bronchoscopies group, dividing the participating centres on the basis of the number of examinations done, to obtain three groups: the 1st group of 0-500 FBS (3 centres); $2^{\text {nd }}$ group of 501-1000 FBS (6 centres); $3^{\text {rd }}$ group > 1000 FBS (9 centres).

A further analysis was carried out, stratifying the centres on the basis of the type and number of interventional procedures performed, to obtain three homogeneous groups depending on the number of procedures. This resulted in the following groups: BB - $1^{\text {st }}$ group 0-200 (7 centres), $2^{\text {nd }}$ group 201- 400 ( 5 centres), $3^{\text {rd }}$ group $>400$ (6 centres). TBB - 1st group 0-100 (10 centres), 2nd group 101200 ( 6 centres), $3^{\text {rd }}$ group $>200$ ( 2 centres). TB $1^{\text {st }}$ group 0-50 (12 centres), $2^{\text {nd }}$ group 50-100 (3 centres), $3^{\text {rd }}$ group $>100$ (3 centres). TBNA - $1^{\text {st }}$ group 0-50 (11 centres), $2^{\text {nd }}$ group 50-100 (3 centres), 3rd group $>100$ ( 4 centres). BAL - 1 st group 0-100(13 centres), $2^{\text {nd }}$ group 100-200 (5 centres). We compared the incidence and type of complication encountered in the groups listed above, calculating the statistical significance by means of the Pearson's chi-square test. The results with a $p<0.05$ are considered as significant.

\section{Results}

The analysed sample consisted of 20,986 endoscopic procedures comprising 10,658 explorative FBS (ESP) $(50.79 \%), 10,328$ non explorative FBS divided as follows: 5,520 bronchial biopsies (BB) (26.30\%), 1,660 transbronchial biopsies (TBB) (7.91\%), 1,127 broncho-alveolar lavages (BAL) (5.37\%), 930 transbronchial aspirating needles (TBNA) (4.43\%), 1,091 Therapeutic bronchoscopies (TB) (5.20\%) comprising NDYAG Laser, Argon-plasma, Electrocautery, Stent positioning. The number of procedures performed in local anesthesia was $19,458(92.72 \%)$, while those in general anesthesia were 1,528 (7.28\%).

The complications that occurred in relation to the endoscopic examinations were found to be 227 (1.08\% of the total of the procedures) (tab. 1) divided into: 20 during anesthesia and pre-medication phase $(0.095 \%), 195$ during the endoscopic procedure $(0.92 \%), 12$ within two hours following FBS $(0.05 \%)$. Thirteen patients had two complications while one patient had three complications. Four mortal complications $(0.02 \%)$ were reported and the causes were: 1 cardiac failure (during the course of Laser treatment), 1 pulmonary edema (during the course of Laser treatment), 1 delayed respiratory failure (laser treatment with prosthesis positioning) and 1 shock in pre-medication (candidate for laser treatment).

In 187 cases $(82.4 \%$ ) a flexible bronchoscope was used, in 37 cases (16.3\%) a rigid bronchoscope was used, while the mixed technique (rigid + flexible) $(1.3 \%)$ was used in three cases. In 186 cases local anesthesia was used (81.9\%), in 51 cases $(27.41 \%)$ Atropine was used for pre-medication, while general anesthesia was used in 41 cases $(18.1 \%) .98 .7 \%$ of the patients who suffered complications were monitored using pulse oxymetry, $30.0 \%$ with ECG and $37.0 \%$ with arterial pressure monitoring.

The four most common complications were: haemorrhage in 93 cases $(41 \%)$ followed by 25 cases $(11.0 \%)$ of oxyhaemoglobin desaturation, 22 cases $(9.77 \%)$ of pneumothorax and 14 cases $(6.22 \%)$ of pulmonary edema. In relation to the type of procedure the diagnostic procedure most 
Table 1. - General table of complications recorded

\begin{tabular}{|c|c|c|c|}
\hline Complications & No. & $\%$ of 227 complications & $\%$ of 20,986 procedures \\
\hline HAEMOPTYSIS $>50 \mathrm{ml}$ & 54 & $23.78 \%$ & $0.26 \%$ \\
\hline HAEMOPTYSIS $<50 \mathrm{ml}$ & 39 & $17.18 \%$ & $0.19 \%$ \\
\hline HYPOXEMIA & 25 & $11.0 \%$ & $0.12 \%$ \\
\hline PNX & 22 & $9.69 \%$ & $0.10 \%$ \\
\hline PULMONARY EDEMA & 14 & $6.2 \%$ & $0.07 \%$ \\
\hline BRONCHOSPASM & 9 & $4.0 \%$ & $0.04 \%$ \\
\hline PREMEDICATION ARRHYTHMIA & 7 & $3.08 \%$ & $0.03 \%$ \\
\hline DYSPNEA & 6 & $2.6 \%$ & $0.03 \%$ \\
\hline HYPERTENSION & 6 & $2.6 \%$ & $0.03 \%$ \\
\hline ARRHYTHMIA & 5 & $2.2 \%$ & $0.02 \%$ \\
\hline TIA & 5 & $2.2 \%$ & $0.02 \%$ \\
\hline VASO-VAGAL EPISODE & 5 & $2.2 \%$ & $0.02 \%$ \\
\hline PREMEDICATION BRONCHOSPASM & 4 & $1.76 \%$ & $0.019 \%$ \\
\hline PREMED. DYSPNEA & 4 & $1.76 \%$ & $0.019 \%$ \\
\hline PREMEDICATION HYPERTENSION & 3 & $1.3 \%$ & $0.014 \%$ \\
\hline CARDIAC ARREST & 3 & $1.3 \%$ & $0.014 \%$ \\
\hline DROWSINESS & 3 & $1.3 \%$ & $0.014 \%$ \\
\hline OTHERS & 13 & 6.08 & 0.055 \\
\hline TOTAL & 227 & $100 \%$ & \\
\hline
\end{tabular}

affected by complications is found to be TBB $(3.43 \%)$, while the one least affected by complications is explorative bronchoscopy $0.43 \%$ (tab. 2). In therapeutic bronchoscopy, we found a $2.84 \%$ incidence of complications.
The percentage distribution of complications in relation to the procedures is shown in table 3 .

Considering the two groups of explorative bronchoscopies and non-explorative bronchoscopies, and relating to the type of study and the

Table 2. - Distribution of number of complications by endoscopic procedure (refers only to complications during the procedure and within 2 hours, 207 cases)

\begin{tabular}{lcc}
\hline \multicolumn{1}{l}{ Type of Procedure } & No. of Complications (tot cases) & \% out of Tot cases \\
\hline Bronchial Biopsy (BB) & $54(5520)$ & $0.97 \%$ \\
\hline Transbronchial Biopsy (TBB) & $57(1660)$ & $3.43 \%$ \\
\hline Explorative FBS & $46(10658)$ & $0.43 \%$ \\
\hline Transbronchial Aspirating Needle (TBNA) & $11(930)$ & $1.18 \%$ \\
\hline Bronchoalveolar Lavage (BAL) & $8(1127)$ & $0.70 \%$ \\
\hline Therapeutic Bronchoscopy (TB)* & 31 (1091) & $2.84 \%$ \\
\hline$*$ Therapeutic Procedures: NYag-Laser 20, Stent 8, Thoracoscopies 6, Argon Plasma 1, Electrocautery 1, Removal of foreign body 1.
\end{tabular}




\begin{tabular}{|c|c|c|c|c|c|c|c|}
\hline & $\mathrm{BB}(\mathbf{5 , 5 2 0 )}$ & ТВB $(1,660)$ & EB $(10,658)$ & TBNA (930) & BAL $(1,127)$ & TB $(1,091)$ & TOT $(\mathbf{2 0 , 9 8 6 )}$ \\
\hline HEMOPTYSIS > $50 \mathrm{ml}$ & $21(0.38 \%)$ & $21(1.26 \%)$ & $1(0.09)$ & 0 & $2(0.17 \%)$ & $9(0.82 \%)$ & $54(0.26 \%)$ \\
\hline HEMOPTYSIS < $50 \mathrm{ml}$ & $19(0.34 \%)$ & $10(0.60 \%)$ & $4(0.03 \%)$ & $5(0.53 \%)$ & 0 & $1(0.82 \%)$ & $39(0.19 \%)$ \\
\hline HYPOXEMIA & $4(0.07 \%)$ & $3(0.18 \%)$ & $13(0.12 \%)$ & 0 & $3(0.26 \%)$ & $2(0.18 \%)$ & $25(0.12 \%)$ \\
\hline PULM. EDEMA & $2(0.03 \%)$ & $1(0.06 \%)$ & $9(0.08 \%)$ & 0 & 0 & $2(0.18 \%)$ & $14(0.07 \%)$ \\
\hline PARTIAL PNX & 0 & $10(0.60 \%)$ & 0 & 0 & 0 & $2(0.18 \%)$ & $12(0.06 \%)$ \\
\hline BRONCHOSPASM & 0 & $1(0.06 \%)$ & $6(0.05 \%)$ & $1(0.10 \%)$ & $1(0.08 \%)$ & 0 & $9(0.04)$ \\
\hline DELAYED PNX & 0 & $6(0.36 \%)$ & 0 & 0 & 0 & $2(0.18 \%)$ & $8(0.04 \%)$ \\
\hline DYSPNEA & $1(0.01 \%)$ & 0 & $3(0.02 \%)$ & $1(0.10 \%)$ & $1(0.08 \%)$ & 0 & $6(0.03 \%)$ \\
\hline HYPERTENSION & 0 & 0 & $4(0.03 \%)$ & $1(0.10 \%)$ & $1(0.08 \%)$ & 0 & $6(0.03 \%)$ \\
\hline ARRHYTHMIAS & $1(0.01 \%)$ & $1(0.06 \%)$ & $1(0.009 \%)$ & 0 & 0 & $2(0.18 \%)$ & $5(0.02 \%)$ \\
\hline TIA & $1(0.01 \%)$ & 0 & $3(0.02 \%)$ & 0 & 0 & $1(0.09 \%)$ & $5(0.02 \%)$ \\
\hline VASO-VAGAL EPISODE & $1(0.01 \%)$ & $1(0.06 \%)$ & 0 & $3(0.32 \%)$ & 0 & 0 & $5(0.02 \%)$ \\
\hline CARDIAC FAILURE & 0 & 0 & 0 & 0 & 0 & $3(0.27 \%)$ & $3(0.01 \%)$ \\
\hline DROWSINESS & $2(0.03 \%)$ & 0 & $1(0.009 \%)$ & 0 & 0 & 0 & $3(0.014 \%)$ \\
\hline $\begin{array}{l}\text { DELAYED SUBCUTANEOU } \\
\text { ENPHYSEMA }\end{array}$ & 0 & 0 & 0 & 0 & 0 & $2(0.18 \%)$ & $2(0.009 \%)$ \\
\hline LASER FIRE & 0 & 0 & 0 & 0 & 0 & $2(0.18 \%)$ & $2(0.009 \%)$ \\
\hline TOTAL PNX & 0 & $2(0.12 \%)$ & 0 & 0 & 0 & 0 & $2(0.09 \%)$ \\
\hline CARBONIZATION STENT & 0 & 0 & 0 & 0 & 0 & $1(0.09 \%)$ & $1(0.004 \%)$ \\
\hline HEART ATTACK & $1(0.01 \%)$ & 0 & 0 & 0 & 0 & 0 & $1(0.004 \%)$ \\
\hline DELAYED INFECTION & 0 & 0 & $1(0.009 \%)$ & 0 & 0 & 0 & $1(0.004 \%)$ \\
\hline DELAYED RESP DEF. & 0 & 0 & 0 & 0 & 0 & $1(0.09 \%)$ & $1(0.004 \%)$ \\
\hline PNEUMOMEDIASTINUM & 0 & 0 & 0 & 0 & 0 & $1(0.09 \%)$ & $1(0.004 \%)$ \\
\hline LIPOTHYMIA & $1(0.01 \%)$ & 0 & 0 & 0 & 0 & 0 & $1(0.004 \%)$ \\
\hline DIZZINESS & 0 & $1(0.06 \%)$ & 0 & 0 & 0 & 0 & $1(0.004 \%)$ \\
\hline TOTAL & $54(0.97 \%)$ & $57(3.43 \%)$ & $46(0.43 \%)$ & $11(1.18 \%)$ & $8(0.70 \%)$ & $31(2.84 \%)$ & $207(0.98 \%)$ \\
\hline
\end{tabular}

number of complications, after eliminating 20 preprocedure complications (4 for explorative and 16 for non explorative), there is a high statistical significance $(p<0.001)$ between the presence of complications and non explorative FBS.

A high statistical significance $(p<0,001)$ is also seen between the presence of complications and the TBB and therapeutic bronchoscopy procedures (tab. 4).

The group of centres which perform $>1,000$ FBS per year reported a greater frequency of complications as compared to the other two $(p<0.0007)$.
The relationship between the number of incidences of complications and the type of interventional procedure showed a higher incidence of complications in the group of centres with the number of procedures between 201-400 for BB $(p<0.009)$ and in the group of centres with the number of procedures between $0-100$ for TBB $(p<$ 0.002 ) (tab. 4). For the groups of centres compared for the other interventional procedures (TBNA, BAL, TB) no statistically significant differences were observed in relation to the distribution of the number of complications in the group. The treat- 
Table 4. - Distribution of complications in relation to procedures in non explorative FBS and distribution of complications in relation to groups stratified by number of Bronchial Biopsies and Trans-Bronchial Biopsies with relative statistical significance

\begin{tabular}{|c|c|c|c|c|}
\hline $\begin{array}{l}\text { Non explorative } \\
\text { examinations }\end{array}$ & $\begin{array}{l}\text { Procedure with } \\
\text { complications }\end{array}$ & $\begin{array}{l}\text { Procedure without } \\
\text { complications }\end{array}$ & TOT & $\begin{array}{c}\text { Statistical } \\
\text { significances }\end{array}$ \\
\hline Transbronchial Biopsies & 57 & 1,603 & 1,660 & $\mathrm{p}<0.001$ \\
\hline Therapeutic Bronchoscopies & 31 & 1,060 & 1,091 & $\mathrm{p}<0.001$ \\
\hline \multicolumn{5}{|c|}{$\begin{array}{l}\text { Stratification of centres by No. } \\
\text { of bronchial biopsies }\end{array}$} \\
\hline 201 to 400 & 23 & 1,410 & 1,433 & $\mathrm{p}<0.009$ \\
\hline \multicolumn{5}{|c|}{$\begin{array}{l}\text { Stratification of centres by No. } \\
\text { of transbronchial biopsies }\end{array}$} \\
\hline Up to 100 & 17 & 238 & 255 & $\mathrm{p}<0.002$ \\
\hline
\end{tabular}

ment was 'medical' for $68.28 \%$, 'endoscopic' for $25.99 \%$ and 'surgical' for $5.72 \%$. The healing percentage was $98.2 \%$.

\section{Discussion}

We conducted a prospective observational study with the aim of evaluating the number of incidence of complications in bronchoscopy in the light of all the new methods developed in the diagnostic as well as the therapeutic fields of bronchoscopy.

The overall incidence of complications was found to be $1.08 \%$ with a mortality of $0.02 \%$. Considering the range of the sample and the complex nature of the endoscopic procedures examined, it may be stated that bronchoscopy, both diagnostic and therapeutic, is a safe method. The mortality recorded, confirming the data already published [6-12], is extremely low. The complications that occurred during the preparation phase for the examination were $20(0.09 \%)$. There are reports in literature of allergic, neurological, cardiovascular and respiratory complications in the pre-medication and anesthesia phase, and these were partly related to the dose of the drug used for the anesthesia or to the drugs used for sedation [13]. Actually there is no standardisation of the type of pre-medication to be used when a bronchoscopy is to be performed [14-15], and in our study too, each participating centre adopted its own protocol. This made it very difficult for us to attempt a statistical correlation between the administration of drugs in pre-medication and the onset of complications, thus highlighting the importance and the need for studies for comparison of the various protocols for preparation of the patients for the endoscopic examinations which make it possible to draw definitive conclusions regarding its danger potential as well as the capacity to prevent complications. A recent publication showed that the application of guidelines in thoracic endoscopic in daily practice can induce a reduction of the incidence of compli- cations [16]; so it is hoped that a shared protocol will be applied. The most frequent complications were haemorrhage, pneumothorax, oxyhaemoglobin desaturation and pulmonary edema. Haemorrhage is confirmed as the most frequent and serious [17] event; no mortal cases were reported, and all were treated successfully, $58.06 \%$ with endoscopic therapy and $41.93 \%$ with medical treatment.

Of the interventional procedures, TBB was found to be the procedure with the highest number of complications, three times higher than $\mathrm{BB}$ and TBNA, and six times higher than BAL and explorative bronchoscopies; this data appears to be in agreement with the data present in literature [18$21]$. There were 22 cases of pneumothorax, treated with thoracic drainage in $59.09 \%$ of the cases according to the indications of the British Thoracic Society [22-23]. The third complication in the order of frequency was oxyhaemoglobin desaturation. There are a number of causes which contribute to the onset of desaturation, from severe alteration of the ventilation-perfusion ratio, hypoventilation linked to sedation, increased resistance due to the introduction of the bronchoscope in the trachea, the onset of bronchospasm and/or inappropriate aspiration movements by the operator [24]. It is vitally important to promptly highlight this event; monitoring using the pulse oxymeter is necessary to immediately highlight this dangerous complication and it must be applied to all patients subjected to bronchoscopy [25-26]. The data of our study highlighted the need for great attention to be paid by endoscopists in monitoring patients during bronchoscopy.

One of the aims of our study was to evaluate the distribution of the incidence of complications with respect to the features of the participating centres, stratified by the number of FBS performed and the type of interventional procedures.

The first result to be recorded was the low incidence of complications in the explorative bronchoscopy group (i.e. carried out without sampling 
and without any therapeutic purpose), which highlights their substantial safety, while there is a high incidence of complications $(p<0.001)$ in the group of non explorative bronchoscopies associated with interventional procedures (TBB, BB, BAL, TBNA, TB). The statistical evaluation of the distribution of the complications in relation to the type of procedure confirmed a high statistical significance in TBB and TB which must be considered as high-risk procedures $(p<0.001)$. The study revealed a high statistical significance in the group of centres which perform $>1,000(p=0.007)$ bronchoscopies. It is logical to think that this group is naturally exposed to the risk of a larger number of complications since it probably treated cases that were more complex and/or with serious co-morbidity. However, a more detailed analysis showed a strong lack of uniformity of performance within this group. In order to homogenise the sample, we further stratified the centres on the basis of the number and type of interventional procedures performed by each. An evaluation of the groups divided by the number of $\mathrm{BB}$ with step 200 shows that a larger number of complications is associated with the second group (step 201-400) $p<0.009$. How can this data be interpreted?

The centres which perform fewer BB generally face simpler problems and usually work with a single bronchoscopist. It is reasonable to think that in intermediate centres with a larger number of procedures, a number of operators are involved who face more complex pathologies on an average but who, individually, perform a smaller number of biopsies. It may be hypothesised that the number of operators, the number of procedures performed by the individual and therefore their experience and training play a fundamental role in the greater incidence of complications. In the third group, the number of $\mathrm{BB}$ performed individually by the operators is higher, providing them with sufficient experience and training to reduce the number of complications to the minimum. This theory seems to be confirmed also by the results of the comparison of the groups with TBB. In the TBB group, the complications are associated with a highly significant frequency in the first group ( $p$ $<0.002$, step 0-100) indicating that the complications are associated with that group of centres which perform fewer TBB. Considering that the execution technique is now standardised, the independent variable may be represented by the operator's skill and experience because of the large number of procedures performed.

The study showed that only $0.05 \%$ of complications appeared at a later stage (within 2 hours after bronchoscopy) and all of them following diagnostic procedures. This extremely low percentage highlights the safety of diagnostic bronchoscopy which therefore does not require hospitalisation but a sufficient period of post-operative observation and clear information regarding the possibility of onset of complications [27-29].

In conclusion, this study shows that bronchoscopy is a safe method with an extremely low incidence of mortality in the diagnostic and thera- peutic phase. The experience and training of the operators may be an important variable in reducing the incidence of complications at least for certain procedures like $\mathrm{BB}$ and $\mathrm{TB}$ and the patients must be provided with the best possible conditions to face the procedure [30-31]. To date, no systematic studies have been conducted which relate the individual risk factors and the probability of the onset of complications; we hope further studies will be conducted in order to establish a correlation between the complications and the risk class of the patients.

Acknowledgements: we thank the following people for their co-operation: Dr. S. Calabro; A. Casalini; S. Cavaliere; G. Donazzan; L.Fecci; A. Fiore Donati; D. Massimo; F. Mazza; G. Michetti; G.F. Milani; R. Pela; F. Ravenna; G. Talmassons; D. Formisano.

\section{References}

1. Creedle W, Smiddy J, Elliott R. Complication of fiberoptic bronchoscopy. Am Rev Respir Dis 1974; 109: 67-72.

2. Suratt P, Smiddy J, Gruber B. Deaths and complication associated with fiberoptic bronchoscopy. Chest 1976; 69: 747-751.

3. Pereira W, Kovnat D, Snider GL. A prospective cooperative study of complication following flexible fiberoptic bronchoscopy. Chest 1978; 73: 813-816.

4. Dreisin RB, Albert RK, Talley PA, et al. Flexible fiberoptic bronchoscopy in the teaching hospital. Chest 1978; 74: 144-149.

5. Burgher LW. Complication and result of transbronchoscopic lung biopsy. Nebr Med J 1979; 64: 247-48.

6. Simpson FG, Arnold AG, Purvis A, et al. Postal survey of bronchoscopic practice by physicians in the United Kingdom. Thorax 1986; 41: 311-317.

7. Smyth CM, Stead RJ. Survey of flexible bronchoscopy in the United Kingdome. Eur Resipir J 2002; 19: 358463.

8. Cavaliere S, Venuta F, Foccoli P, Toninelli C, La Face B. Endoscopic treatement of malignant airway obstructions in 2,008 patients. Chest 1996; 110: 1536-42.

9. Santos RS, Raftopoulos Y, Keenan RJ, Halal A, Maley RH, Landreneau RJ. Bronchoscopic palliation of primary lung cancer: single or multimodality therapy? Surg Endosc 2004; 18: 931-6.

10. Jin F, Mu D, Chu D, Fu E, Xie Y, Liu T. Severe complications of bronchoscopy. Respiration 2008; 76: 429-33.

11. Kaparianos A, Argyropoulou E, Sampsonas F, et al. Indications, results and complications of flexible fiberoptic bronchoscopy: a 5-year experience in a referral population in Greece. Eur Rev Med Pharmacol Sci 2008; 12: 355-63.

12. Geraci G, Pisello F, Sciumè C, Li Volsi F, Romeo M, Modica G. Complication of flexible fiberoptic bronchoscopy. Literature review. Ann Ital Chir 2007; 78: 183-92.

13. Honeybourne D, Babb J, Bowie P, et al. British Toracic Society guidelines on diagnostic flexible bronchoscopy. Thorax 2001; 56: i1-i21.

14. Pickles J, Jeffrey M, Datta A, Jeffrey AA. Is preparation for bronchoscopy optimal? Eur Respir J 2003; 22: 203-6.

15. Jantz MA. The old and the new of sedation for bronchoscopy. Chest 2009; 135: 4-6. 
16. Dransfield MT, Garver RI, Weill D. Standardized guidelines for surveillance bronchoscopy reduce complications in lung transplant recipients. J Heart Lung Transplant 2004; 23: 110-4.

17. Cordasco EM, Metha AC, Ahmad M. Bronchoscopically induced bleeding. A summary of nine years Cleveland clinic experience and review of the literature. Chest 1991 100: 1125-1130.

18. Hanson RR, Zavala DC, Rhodes ML, Keim LW, Smith JD. Transbronchial biopsy via flexible fiberoptic bronchoscope; result in 164 patients. Am Rev Respir Dis 1976; 114: 67-72.

19. Casoni GL, Gurioli C, Chhajed PN, et al. The value of transbronchial lung biopsy using jumbo forceps via rigid bronchoscope in diffuse lung disease. Monaldi Arch Chest Dis 2008; 69: 59-64.

20. Bulpa PA, Dive AM, Mertens L, et al. Combined bronchoalveolar lavage and transbronchial lung biopsy: safety and yield in ventilated patients Eur Respir $J$ 2003; 21: 489-94.

21. Pincus PS, Kallenbach JM, Hurwitz MD, et al. Transbronchial biopsy during mechanical ventilation. Crit Care Med 1987; 15: 1136-9.

22. M Henry, T Arnold and J Harvey Pleural Diseases Group, Standards of Care Committee, British Thoracic Society. BTS guidelines for the management of spontaneous pneumothorax. Thorax 2003; 58 Suppl 2: 39-52.

23. D Laws, E Neville and J Duffy Pleural Diseases Group, Standards of Care Committee, British Thoracic Society.
BTS guidelines for the insertion of a chest drain. Tho$\operatorname{rax} 2003$; 58 Suppl 2: 53-9.

24. Matsushima Y, Jones RL, King EG, Moysa G, Alton JDM. Alterations in pulmonary mechanics and gas exchange during routine fiberoptic bronchoscopy. Chest 1984; 86: 184-188.

25. Milman N, Faurschou P, Grode G, Jorgensen A. Pulse oximetry during fibreoptic bronchoscopy in local anaesthesia: frequency of hypoxaemia and effect of oxygen supplementation. Respiration 1994; 61: 342-7.

26. Pedersen T, Dyrlund Pedersen B, Møller AM. Pulse oximetry for perioperative monitoring. Cochrane Database Syst Rev 2003; (3): CD002013.

27. Izbicki G, Shitrit D, Yarmolovsky A, et al. Is routine chest radiography after transbronchial biopsy necessary?: A prospective study of 350 cases. Chest 2006; 129: 1561-4.

28. Frazier WD Pope TL Jr, Findley LJ. Pneumothorax following transbronchial biopsy. Low diagnostic yield with routine chest roentgenograms. Chest 1990; 97: 539-40.

29. Hernandez Blasco L, Sanchez Hernandez IM, Villena Garrido V, et al. Safety of the trans-bronchial biopsy in outpatients. Chest 1991; 99: 562-5.

30. Barlesi F, Dissard-Barriol E, Gimenez C, Doddoli C, Greillier L, Kleisbauer JP. [Tolerance of fiberoptic bronchoscopy by self-administered questionnaire: in the words of the patients]. Rev Mal Respir 2003; 20: 335-40.

31. Mitsumune T, Senoh E, Adachi M. Prediction of patient discomfort during fibreoptic bronchoscopy. Respirology 2005; 10: 92-6.

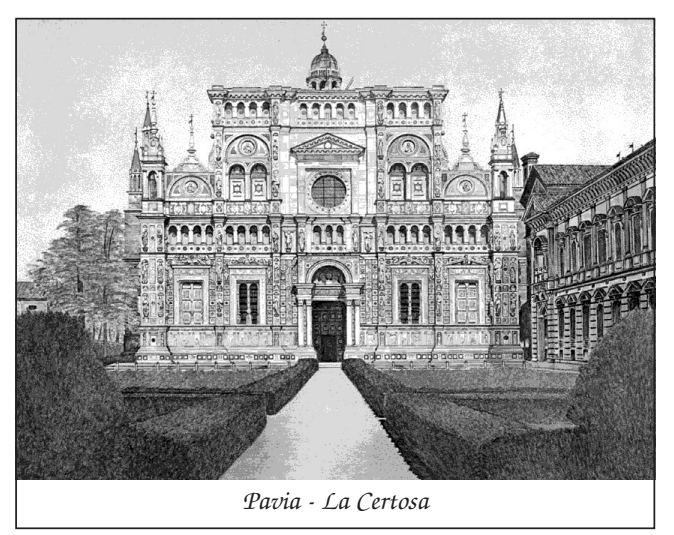

